\title{
Association between carotid intima-media thickness and ulcerative colitis: a systematic review and meta- analysis
}

Ladan Goshayeshi ${ }^{1,2}$, Ali Bahari ${ }^{1,2}$, Farnaz Torabian ${ }^{3}$, Kasra Molooghi $^{4}$, Ermia Musavi Mohammadi ${ }^{4}$, Mehrdad Sahranavard ${ }^{5}$, Hoda Hosseinzadeh Maleki ${ }^{6}$, Zahra Sabzeh Noughabi ${ }^{7}$, Benyamin Hoseini ${ }^{8}$

${ }^{1}$ Department of Gastroenterology and Hepatology, Faculty of Medicine, Mashhad University of Medical Sciences, Mashhad, Iran

${ }^{2}$ Gastroenterology and Hepatology Research Center, Mashhad University of Medical Sciences, Mashhad, Iran

${ }^{3}$ Student Research Committee, Islamic Azad University, Mashhad Branch, Mashhad, Iran

${ }^{4}$ Student Research Committee, Faculty of Medicine, Mashhad University of Medical Sciences, Mashhad, Iran

${ }^{5}$ Student Research Committee, School of Pharmacy, Mashhad University of Medical Sciences, Mashhad, Iran

${ }^{6}$ Student Research Committee, Faculty of Medicine, North Khorasan University of Medical Sciences, Bojnurd, Iran

${ }^{7}$ Clinical Research Development Unit (CRDU), 22 Bahman Hospital, Gonabad University of Medical Sciences, Gonabad, Iran

${ }^{8}$ Department of Health Information Technology, Neyshabur University of Medical Sciences, Neyshabur, Iran

Type of article: Meta-analysis

\begin{abstract}
Background: Early detection of atherosclerosis is an essential means of decreasing cardiovascular events and its associated mortality. Systemic inflammatory diseases such as ulcerative colitis (UC), are thought to be a contributing factor to atherosclerosis due to the rise of inflammatory cytokines.

Objective: The aim of this systematic review and meta-analysis was to assess the association between atherosclerosis and UC.

Methods: This systematic review and meta-analysis was performed in February 2017 with no date restrictions. PubMed, Cochrane Library and Embase were searched to discover all available observational studies on atherosclerosis among UC patients. The STROBE criteria were used to assess the quality of the included articles. Heterogeneity was assessed by the I-square statistic and publication bias with funnel plot and Egger's regression test. Overall summary mean difference was calculated as study effect size using random effect model. Comprehensive Meta-Analysis Software version 2.2 was used to perform analyses.

Results: A total of 5 articles met our eligibility criteria. We included a sum of 206 UC patients and 229 non-UC individuals in our review with a mean difference of c-IMT ranged from $0.03 \pm 0.0$ to $0.16 \pm 0.03 \mathrm{~mm}$, and a pooled mean difference of $0.127 \mathrm{~mm}\left(95 \%\right.$ CI $\left.0.058-0.195: \mathrm{I}^{2}=90.266 \%\right)$. Potential publication bias did not exist for the UC.

Conclusion: Our findings showed significant differences in carotid intima-media thickness among UC and NonUC groups, making c-IMT a viable choice as a predicting marker for atherosclerosis. Thus, we suggest that policy makers assess and consider its application in future protocols for the follow up and management of UC patients.

Keywords: Inflammatory bowel disease, Ulcerative colitis, Carotid intima-media thickness, Atherosclerosis, Cardiovascular disease
\end{abstract}

\section{Introduction}

Ulcerative colitis (UC), is a subtype of inflammatory bowel disease (IBD), which is a chronic and progressive inflammatory disease of the gastrointestinal tract (1). The reported prevalence of UC in the United States has been

\section{Corresponding author:}

Benyamin Hoseini, Department of Health Information Technology, Neyshabur University of Medical Sciences, Neyshabur, Iran.

Tel: +985142254170, Fax:+985142254171, E-mail: hoseinib1@nums.ac.ir, and Binyamin.hoseini@gmail.com

Received: March 19, 2018, Accepted: May 19, 2018, Published: June 2018

iThenticate screening: May 20, 2018, English editing: May 28, 2018, Quality control: June 15, 2018

This article has been reviewed / commented by three experts

(C) 2018 The Authors. This is an open access article under the terms of the Creative Commons Attribution-NonCommercialNoDerivs License, which permits use and distribution in any medium, provided the original work is properly cited, the use is non-commercial and no modifications or adaptations are made. 
37 to 246 cases per 100,000 population with the Incidence Rate of 2.2 to 14.3 cases per 100,000 person-years (2). Changes in the balance between regulatory and inflammatory cytokines cause the inflammatory process, which leads to functional and structural changes in the vascular endothelium and eventually atherosclerosis $(3,4)$. Atherosclerosis is thought to be the hallmark of cardiovascular diseases, which is one of the leading causes of mortality worldwide $(5,6)$. Intima-media thickness (IMT) is thought to be an initial structural marker for atherosclerotic lesions, and any rise in IMT of the carotid artery can be a considerable predicting factor in any future cardiovascular diseases (7). Its measurement by ultrasonography is rather an easy, safe, low-cost, and reproducible method (8). When compared with the general population, IBD and UC patients show a higher risk in the development of early atherosclerosis and an increase in c-IMT (9-11). An increase in the rates of cardiovascular diseases (CVD) and/or CVD events in UC and IBD patients has been demonstrated in several epidemiological studies (12). The effect of systemic inflammatory diseases on the development of atherosclerosis has been a topic of debate in recent years (13). The management and follow-up protocols for UC patients can be influenced considerably by the verification of such association (12). In 2013, Theocharidou et al. and in 2016, Guo-Cui Wu et al. respectively performed a systematic review and a systematic review and meta-analysis on the available literature on IBD patients and their c-IMT measurements $(6,12)$. However, these articles lacked accuracy due to the inclusion of patients with hypertension and diabetes mellitus. Moreover, we tried to analyze additional data such as insulin resistance and fasting blood glucose (FBS) to estimate the impact of some confounding factors on our results. Additionally, the current review focuses on UC patients rather than all IBD patients, with the aim of making the results more homogenous. Selection of UC rather than IBD or Crohn's disease (CD) was based on the suggestion of the positive results on the increase of c-IMT in UC patients, and higher prevalence of UC rather than the CD. Even though only a limited amount of literature has been conducted solely on UC, the study aimed to conduct a systematic review and meta-analysis of the available observational studies on c-IMT in cases with UC without history of CVD in order to assess the association between c-IMT and UC compared to healthy individuals.

\section{Material and Methods}

This systematic review and meta-analysis was carried out according to the Meta-analysis of Observational Studies in Epidemiology (MOOSE) guideline (14).

\subsection{Literature search strategy}

In February 2017, a detailed systemic search strategy was applied to search all the relevant literature in PubMed, Embase, and the Cochrane library by two separate individuals without publication year restriction. Medical subject headings (MeSH) terms of "ulcerative colitis", "inflammatory bowel disease", "atherosclerosis", and "carotid intima-media thickness" were included in the final search. MeSH terms of "ulcerative colitis", and "inflammatory bowel disease" were combined together into one category using the disjunction "OR", and MeSH terms of "atherosclerosis" and "carotid intima-media thickness" were combined into another category. The two categories were combined together by the conjunction "AND" in any possible combination, to specify search results. This was supplemented by a review of references of included studies and review articles.

\subsection{Eligibility criteria}

\subsubsection{Inclusion criteria:}

Original articles were selected if they fulfilled the following criteria: 1) humans were involved; 2) patients with UC or IBD were included; 3) a control group of healthy individuals was included; 4) included patients with UC were not as part of a disease group; 5) measurement of carotid media intima-thickness was performed.

\subsubsection{Exclusion criteria:}

The exclusion criteria of studies were as follows: 1) non-primary studies such as (systematic) reviews, editorials, comments, guidelines and letters to editors; 2) irretrievable articles; 3 ) studies that lacked the data of interest such as carotid intima-media thickness (c-IMT); 4) all the papers that had not separated nor analyzed the data of patients with ulcerative colitis from IBD; 5) studies that include duration of less than one year after diagnosis; 6) studies that involve individuals aged below 18 years; 7) animal studies.

\subsubsection{Patient Characteristics:}

The diagnosis of UC was based on 4 criteria, histological and pathological findings, clinical signs and symptoms, radiological findings, and endoscopic confirmation. All patients were confirmed by all 4 criteria. C-IMT was measured by two different means of Doppler ultrasonography and B-mode ultrasonography, whose results are comparable to each other. Patients with the diagnosis of UC were also added from papers which studied IBD patients as a primary objective, but had separated the data of UC and CD. Table 1 specifies the aforementioned articles. 
Table 1. The c-IMT finding of patients with $\mathrm{UC}$ and Non-UC in included studies

\begin{tabular}{|l|l|l|l|l|l|l|l|l|l|}
\hline $\begin{array}{l}\text { Ref. } \\
\text { no. }\end{array}$ & $\begin{array}{l}\text { Sample } \\
\text { size*** }\end{array}$ & $\begin{array}{l}\text { UC* } \\
(\mathrm{n})\end{array}$ & $\begin{array}{l}\text { Non- } \\
\text { UC (n) }\end{array}$ & $\begin{array}{l}\text { c-IMT } * *(m) \\
\text { UC }\end{array}$ & Non-UC & $\begin{array}{l}\text { Mean } \\
\text { difference }\end{array}$ & p-value & $\begin{array}{l}\text { STROBE } \\
\text { score }\end{array}$ & Comments \\
\hline 15 & 50 & 19 & 31 & $0.55 \pm 0.1$ & $0.51 \pm 0.06$ & $0.04 \pm 0.04$ & 0.14 & 28 & $\begin{array}{l}\text { c-IMT was not significantly higher in } \\
\text { patients with UC }\end{array}$ \\
\hline 1 & 67 & 37 & 30 & $0.86 \pm 0.15$ & $0.55 \pm 0.29$ & $0.31 \pm 0.14$ & $<0.001$ & 30 & $\begin{array}{l}\text { c-IMT was significantly higher in } \\
\text { patients with UC }\end{array}$ \\
\hline 16 & 58 & 16 & 42 & $0.61 \pm 0.06$ & $0.52 \pm 0.06$ & $0.09 \pm 0.0$ & $<0.0005$ & 29 & $\begin{array}{l}\text { c-IMT was significantly higher in the } \\
\text { UC patients than in the non-UCs }\end{array}$ \\
\hline 17 & 120 & 60 & 60 & $0.68 \pm 0.07$ & $0.52 \pm 0.04$ & $0.16 \pm 0.03$ & 0.001 & 33 & $\begin{array}{l}\text { c-IMT was significantly higher in the } \\
\text { UC patients than in the non-UC }\end{array}$ \\
\hline 18 & 140 & 74 & 66 & $0.44 \pm 0.8$ & $0.41 \pm 0.08$ & $0.03 \pm 0.0$ & 0.152 & 29 & $\begin{array}{l}\text { c-IMT was not significantly higher in } \\
\text { patients with UC }\end{array}$ \\
\hline
\end{tabular}

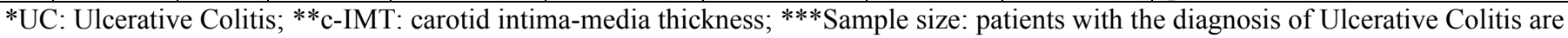
analyzed separately from IBD patients in this table, but the number of non-UC patients were initially selected according to the sum of IBD patients in the original article. Total sample size: 435, Total UC: 206, Total non-UC group: 229

\subsection{Study selection}

EndNote X7 (Thomson Reuters, New York, NY, USA), reference management software, was applied to aggregate all the search strategy returns together. Two reviewers screened the exported articles in EndNote and compared them with the inclusion and exclusion criteria independently. The points of conflict were resolved by discussion. A brief flow diagram of the articles included in the review is outlined in Figure 1.

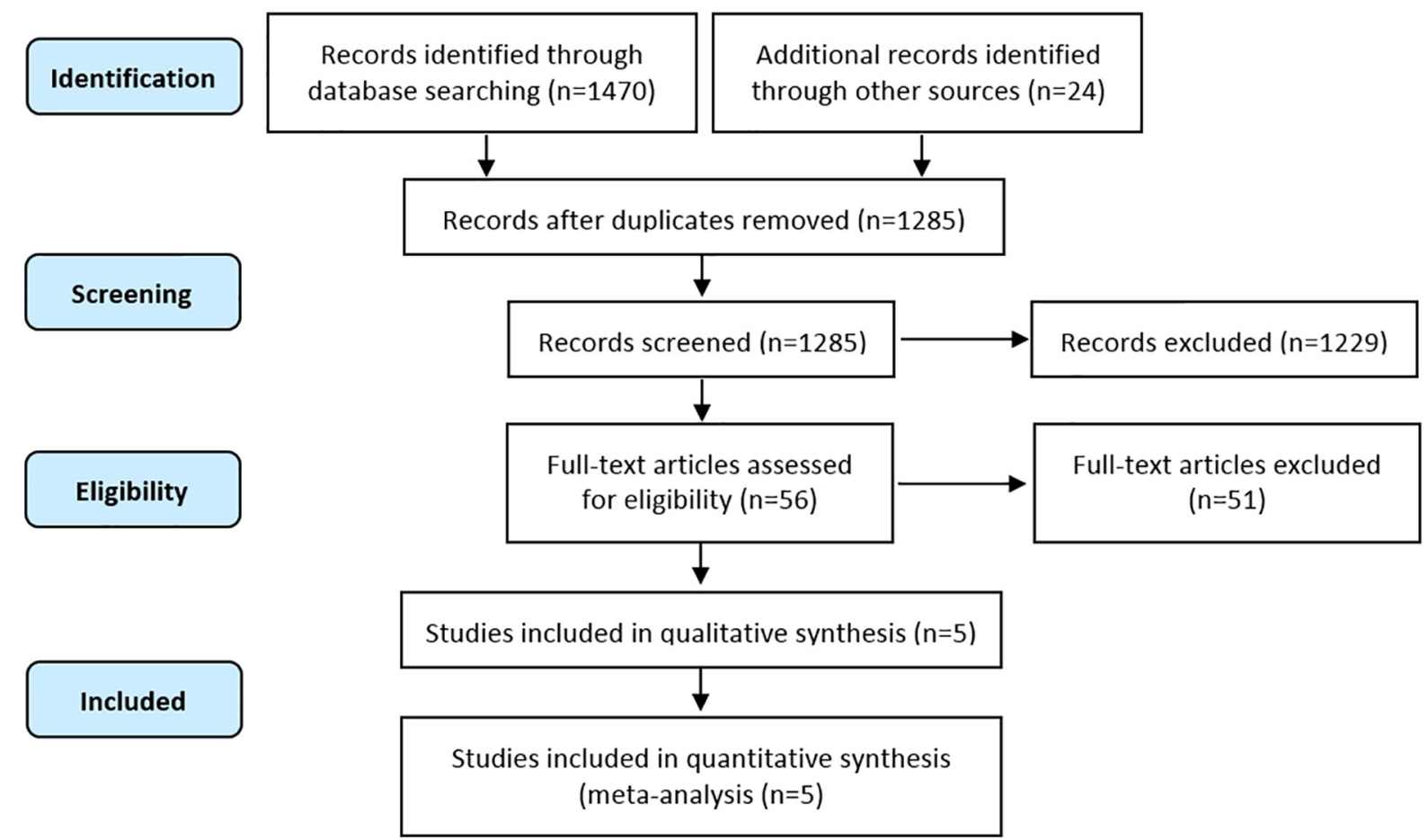

Figure 1. Flow diagram for study selection.

\subsection{Data extraction}

Two reviewers performed data extraction independently and any discrepancy was solved by consensus. In each study, the following data items were extracted in patients with UC and control (non-UC) groups : sample size, study design, c-IMT, cf-PWV (carotid-femoral pulse wave velocity), FMD (flow-mediated dilatation), HOMA-IR (homeostasis model of assessment of insulin resistance), CRP (C-reactive protein), ESR (erythrocyte sedimentation rate), HDL (high density lipoprotein), LDL (low density lipoprotein), TG (triglyceride), FBS (fasting blood sugar), mean \pm SD of age, duration of disease, BMI (body mass index), smoking, number of male and female participants and drugs. 


\subsection{Quality Assessment}

Two reviewers critically appraised each study on their methodological quality. Data of the included studies were gathered in a data-extraction form based on the STROBE (Strengthening the Reporting of Observational studies in Epidemiology) criteria (19). Calculated score for each study is as outlined in Table 1.

\subsection{Data analysis}

To assess the association, overall summary estimates have been calculated using random effect models. All continuous data are summarized as mean difference along with $95 \%$ confidence intervals (CIs). Heterogeneity was quantified with the inconsistency index $\left(\mathrm{I}^{2}\right)(20)$. A funnel plot and Egger's regression test were used to assess publication bias (21). Comprehensive Meta-Analysis (CMA) software version 2.2 was used to perform analyses with a $p$-value $<0.05$ considered statistically significant.

\section{Results}

The initial search yielded 1,494 articles, among which 209 were removed after duplication finding. Afterwards, 1,229 of 1,285 remaining papers were excluded after scanning. Of the 56 candidate papers, an additional 51 were then omitted on the basis of their full text eligibility. Therefore, full text of 5 appropriate documents had been evaluated for the detection of subclinical atherosclerosis in patients with UC for further assessment. The process of literature selection is demonstrated in detail in Figure1.

\subsection{General information}

In the current review of the 5 articles, 2 of them reported c-IMT measurement only in patients with UC $(1,18)$. The remaining studies reviewed IBD patients, but had separated the data of UC from IBD. IBD patients in those studies were 435 which included 206 UC patients. Control groups consisted 229 non-UC or healthy individuals. All included studies had a case-control design and all of them diagnosed UC based on the entire 4 criteria of diagnosis: clinical features, endoscopic and radiological findings and pathological evidence. Table 2 shows parameters such as disease duration, age, gender, BMI, smoking, cf-PWV and FMD that are relative factors for UC.

Table 2. Demographic, ultrasonography and drug history data of patients with UC and non-UC in included studies.

\begin{tabular}{|c|c|c|c|c|c|c|c|c|c|c|c|c|c|c|}
\hline \multirow{2}{*}{$\begin{array}{l}\text { Ref. } \\
\text { no. }\end{array}$} & \multirow[t]{2}{*}{ Drugs* } & \multirow{2}{*}{$\begin{array}{l}\text { Disease } \\
\text { duration } \\
\text { (years)* }\end{array}$} & \multicolumn{2}{|c|}{ Age (years) } & \multicolumn{2}{|l|}{$\mathrm{M} / \mathrm{F}$} & \multicolumn{2}{|c|}{ BMI $\left(\mathrm{kg} / \mathrm{m}^{2}\right)$} & \multicolumn{2}{|c|}{ Smoking } & \multicolumn{2}{|c|}{ cfPWV $(\mathrm{m} / \mathrm{s})$} & \multicolumn{2}{|c|}{ FMD (\%) } \\
\hline & & & $\mathrm{UC}$ & $\begin{array}{l}\text { Non- } \\
\text { UC }\end{array}$ & $\mathrm{UC}$ & $\begin{array}{l}\text { Non- } \\
\text { UC }\end{array}$ & $\mathrm{UC}$ & $\begin{array}{l}\text { Non- } \\
\text { UC }\end{array}$ & UC & $\begin{array}{l}\text { Non- } \\
\text { UC }\end{array}$ & $\mathrm{UC}$ & $\begin{array}{l}\text { Non- } \\
\text { UC }\end{array}$ & $\mathrm{UC}$ & Non-UC \\
\hline 15 & $\mathrm{~N} / \mathrm{A}$ & $\mathrm{N} / \mathrm{A}$ & $\begin{array}{l}36.4 \pm \\
8.9\end{array}$ & $\begin{array}{l}32.7 \pm \\
6.9\end{array}$ & $10 / 9$ & $16 / 15$ & N/A & $\mathrm{N} / \mathrm{A}$ & 1 & 9 & $\mathrm{~N} / \mathrm{A}$ & N/A & $10 . \pm 5.4$ & $18.7 \pm 9.2$ \\
\hline 1 & $\begin{array}{l}\text { Aminosalicylates, } \\
\text { Corticosteroid or } \\
\text { immunosuppressive, } \\
\text { Infliximab }\end{array}$ & N/A & $48 \pm 15$ & $45 \pm 8$ & $21 / 16$ & $9 / 21$ & $\begin{array}{l}27.0 \pm \\
4.4\end{array}$ & $\begin{array}{l}27.5 \pm \\
4.1\end{array}$ & 6 & 4 & $\begin{array}{l}8.94 \pm \\
2.98\end{array}$ & $\begin{array}{l}7.17 \pm \\
1.73\end{array}$ & N/A & N/A \\
\hline 16 & $\begin{array}{l}\text { 5-ASA, Azathioprine, } \\
\text { Anti-TNF-a, } \\
\text { Corticosteroids }\end{array}$ & 6.5 & $\begin{array}{l}33.9 \pm \\
11.4\end{array}$ & $\begin{array}{l}36.3 \pm \\
10.7\end{array}$ & $7 / 9$ & $20 / 22$ & $\begin{array}{l}24.4 \pm \\
6\end{array}$ & $\begin{array}{l}23.2 \pm \\
4.2\end{array}$ & 1 & 22 & $\mathrm{~N} / \mathrm{A}$ & $\mathrm{N} / \mathrm{A}$ & $\mathrm{N} / \mathrm{A}$ & $\mathrm{N} / \mathrm{A}$ \\
\hline 17 & $\begin{array}{l}\text { Mesalamine, } \\
\text { azathioprine }\end{array}$ & $\begin{array}{l}7.24 \pm 2.0 \\
5\end{array}$ & $\begin{array}{l}35.6 \pm \\
6.2\end{array}$ & $\begin{array}{l}34.9 \pm \\
5.2\end{array}$ & $33 / 27$ & $32 / 28$ & $\begin{array}{l}20.4 \pm \\
1.5\end{array}$ & $\begin{array}{l}21.0 \pm \\
1.7\end{array}$ & N/A & N/A & $\mathrm{N} / \mathrm{A}$ & N/A & N/A & N/A \\
\hline 18 & $\begin{array}{l}\text { Mesalazine, Steroid, } \\
\text { Azathiopurine, Anti- } \\
\text { TNF }\end{array}$ & $4.1 \pm 3.9$ & $\begin{array}{l}32.9 \pm \\
8.4\end{array}$ & $\begin{array}{l}30.9 \pm \\
7\end{array}$ & $54 / 20$ & $45 / 21$ & $\begin{array}{l}24.2 \pm \\
3.8\end{array}$ & $\begin{array}{l}23.6 \pm \\
2.8\end{array}$ & 1 & 2 & $\begin{array}{l}8.13 \pm \\
1.61\end{array}$ & $\begin{array}{l}6.85 \pm \\
0.95\end{array}$ & $9.6 \pm 5.1$ & $15.1 \pm 9.7$ \\
\hline
\end{tabular}

M/F, Male/Female; BMI, Body Mass Index; cf-PWV, carotid-femoral Pulse Wave Velocity; FMD, Flow-Mediated Dilation; N/A, Not available.

\subsection{The UC characteristics}

The number of studied UC patients ranged from 16 to 74 in the included documents, among which 125 (59.8\%) were male and $81(40.2 \%)$ were female. The mean age ranged from $32.9 \pm 8.4$ to $48 \pm 15$ years. In 2 articles, the disease duration was not reported. Disease duration in other articles was 4.1 to 7.24 years. The mean \pm SD of body mass BMI was $20.4 \pm 1.5$ to $27.5 \pm 4.1 \mathrm{~kg} / \mathrm{m}^{2}$. In 1 study, the mean BMI was not reported. With regard to smoking, 1 study did not report the number of smokers, and from $125 \mathrm{UC}$ patients in remaining studies, 9 smokers, and in nonUC groups, 37 smokers were reported. In the only two studies which had reported the cf-PWV, levels were $8.94 \pm$ 2.98 and $8.13 \pm 1.61 \mathrm{~m} / \mathrm{Sec}$ in the patients with $\mathrm{UC}$, and $7.17 \pm 1.73$ and $6.85 \pm 0.95 \mathrm{~m} / \mathrm{Sec}$ in the healthy subjects. In 3 articles FMD was not reported and in the 2 articles FMD levels in patients with UC compared with non-UC subjects were $10.3 \% \pm 5.4 \%$ and $9.6 \% \pm 5.1 \%$. Regarding drug history in UC patients, Kayahan et al. had not reported any drug 
history (15) and in other studies use of the following drugs were mentioned: Aminosalicylates, Corticosteroid or Immunosuppressive, Infliximab, Azathioprine, Anti-TNF-a, Mesalamine.

\subsection{The CVD risk factors}

In the five studies we reviewed, biochemical parameters and inflammatory markers such as ESR, CRP, HDL-c, LDL-c, TG, FBS, HOMA-IR were gathered in Table 3. Theocharidou et al. (16) did not report ESR and in others the mean \pm SD ESR for UC patients was $21.1 \pm 11.3 \mathrm{~mm} / \mathrm{h}$ to $41.0 \pm 15.7 \mathrm{~mm} / \mathrm{h}$, and $8.4 \pm 5.2 \mathrm{~mm} / \mathrm{h}$ to $15.1 \pm 4.5 \mathrm{~mm} / \mathrm{h}$ in non-UC patients. The CRP, with mean levels ranged from $0.34 \pm 0.24$ to $10.2 \pm 19.7 \mathrm{mg} / \mathrm{dL}$ and one study had not measured CRP levels (17). The HDL-c levels ranged from $40.2 \pm 5.4$ to $53 \pm 12 \mathrm{mg} / \mathrm{dL}$, however, one study had reported HDL-c, LDL-c and TG levels by mmol/L, which was converted and calculated into mg/dL (17). Mean LDL-c levels were $79.6 \pm 10.0$ to $135 \pm 39 \mathrm{mg} / \mathrm{dL}$ in four studies. Kayahan et al. had not reported LDL-c levels. Mean triglyceride levels ranged from $87.7 \pm 9.7$ to $135 \pm 83 \mathrm{mg} / \mathrm{dL}$ in four studies. Mean FBS level was only reported in two papers which were between $90.4 \pm 7.0$ and $104 \pm 18 \mathrm{mg} / \mathrm{dL}$. In one study, HOMA-IR was reported $2.94 \pm 0.99$ in UC patients and $1.56 \pm 0.20$ in healthy subjects (17). In other studies, HOMA-IR was not reported. Mean of c-IMT shown in Table 1 depicts that patients with UC had a thickness of $0.44 \pm 0.8$ to $0.86 \pm 0.15 \mathrm{~mm}$ versus $0.41 \pm 0.08$ to $0.66 \pm 0.16$ $\mathrm{mm}$ in control group. In two studies, c-IMT was not significantly higher in patients with UC rather than healthy people but in the remaining three, the differences were significant.

Table 3. Biochemical and inflammatory data of patients with UC and non-UC in included studies.

\begin{tabular}{|c|c|c|c|c|c|c|c|c|c|c|c|c|c|c|}
\hline \multirow{2}{*}{$\begin{array}{l}\text { Ref. } \\
\text { no. }\end{array}$} & \multicolumn{2}{|c|}{$\operatorname{ESR}(\mathrm{mm} / \mathrm{h})$} & \multicolumn{2}{|c|}{ CRP (mg/dL) } & \multicolumn{2}{|c|}{ HDL-c (mg/dL) } & \multicolumn{2}{|c|}{ LDL-c (mg/dL) } & \multicolumn{2}{|c|}{ TG (mg/dL) } & \multicolumn{2}{|c|}{ FBS (mg/dL) } & \multicolumn{2}{|c|}{ HOMA.IR } \\
\hline & UC & Non-UC & $\mathrm{UC}$ & Non-UC & $\mathrm{UC}$ & \begin{tabular}{|l} 
Non- \\
UC
\end{tabular} & $\mathrm{UC}$ & \begin{tabular}{|l|} 
Non- \\
UC
\end{tabular} & $\mathrm{UC}$ & $\begin{array}{l}\text { Non- } \\
\text { UC }\end{array}$ & $\mathrm{UC}$ & $\begin{array}{l}\text { Non- } \\
\text { UC }\end{array}$ & $\mathrm{UC}$ & $\begin{array}{l}\text { Non- } \\
\text { UC }\end{array}$ \\
\hline 15 & $\begin{array}{l}21.1 \\
\pm 11.3\end{array}$ & $8.4 \pm 5.2$ & $6.7 \pm 5.7$ & $\begin{array}{l}1.55 \\
\pm 1.89\end{array}$ & $\mathrm{~N} / \mathrm{A}$ & N/A & $\mathrm{N} / \mathrm{A}$ & N/A & $\mathrm{N} / \mathrm{A}$ & N/A & $\mathrm{N} / \mathrm{A}$ & N/A & N/A & N/A \\
\hline 1 & $\begin{array}{l}22.4 \\
\pm 18.4\end{array}$ & $\begin{array}{r}13.5 \\
\pm 7.3 \\
\end{array}$ & $\begin{array}{l}0.83 \\
\pm 1.19\end{array}$ & $\begin{array}{l}0.34 \\
\pm 0.24\end{array}$ & $\begin{array}{l}45 \\
\pm 11\end{array}$ & $45 \pm 9$ & $\begin{array}{l}135 \\
\pm 39\end{array}$ & $126 \pm 36$ & $\begin{array}{l}135 \\
\pm 66\end{array}$ & $\begin{array}{l}135 \\
\pm 83\end{array}$ & $\begin{array}{l}104 \\
\pm 18 \\
\end{array}$ & $\begin{array}{l}102 \\
\pm 16\end{array}$ & $\mathrm{~N} / \mathrm{A}$ & $\mathrm{N} / \mathrm{A}$ \\
\hline 16 & N/A & $\mathrm{N} / \mathrm{A}$ & $\begin{array}{l}3.2(0.1- \\
36.2)\end{array}$ & $\begin{array}{l}1.04(0.9- \\
1.21)\end{array}$ & $\begin{array}{l}53 \\
\pm 12\end{array}$ & $49 \pm 11$ & $\begin{array}{l}114 \\
\pm 36\end{array}$ & $125 \pm 32$ & $\begin{array}{l}90 \\
\pm 46\end{array}$ & $\begin{array}{l}98.3 \\
\pm 49.7\end{array}$ & $\mathrm{~N} / \mathrm{A}$ & $\mathrm{N} / \mathrm{A}$ & $\mathrm{N} / \mathrm{A}$ & N/A \\
\hline 17 & $\begin{array}{l}41.06 \\
\pm 15.76\end{array}$ & $\begin{array}{l}15.14 \\
\pm 4.54\end{array}$ & $\mathrm{~N} / \mathrm{A}$ & $\mathrm{N} / \mathrm{A}$ & $\begin{array}{l}40.2 \\
\pm 5.4\end{array}$ & $\begin{array}{l}40.2 \\
\pm 5.4\end{array}$ & $\begin{array}{l}79.6 \\
\pm 10.0\end{array}$ & $\begin{array}{l}79.3 \\
\pm 10.8\end{array}$ & $\begin{array}{l}87.7 \\
\pm 9.7\end{array}$ & $\begin{array}{l}87.7 \\
\pm 8.8\end{array}$ & $\begin{array}{l}94.1 \\
\pm 6.6\end{array}$ & $\begin{array}{r}90.4 \\
\pm 7.0 \\
\end{array}$ & \begin{tabular}{|l|}
2.94 \\
\pm 0.99
\end{tabular} & $\begin{array}{l}1.56 \\
\pm 0.20\end{array}$ \\
\hline 18 & $\begin{array}{l}23.7 \\
\pm 22.6\end{array}$ & $9.6 \pm 8$ & $\begin{array}{l}10.2 \\
\pm 19.7\end{array}$ & $3.1 \pm 3.7$ & $\begin{array}{l}46.7 \\
\pm 12.0\end{array}$ & $\begin{array}{l}50.3 \\
\pm 15.4\end{array}$ & $\begin{array}{l}103.9 \\
\pm 32.4\end{array}$ & $\begin{array}{l}103.6 \\
\pm 28.2\end{array}$ & $\begin{array}{l}117.1 \\
\pm 51.9\end{array}$ & $\begin{array}{l}123.3 \\
\pm 73.3\end{array}$ & $\mathrm{~N} / \mathrm{A}$ & N/A & N/A & N/A \\
\hline
\end{tabular}

ESR, erythrocyte sedimentation rate; CRP, C-reactive protein; HDL-c, high density lipoprotein; LDL, low density lipoprotein; TG, triglyceride; FBS, fasting blood glucose; HOMA.IR, Homeostasis model assessment of insulin resistance; N/A, Not available.

\subsection{Meta-analysis findings}

Five observational studies involving 435 people were included in the meta-analysis. There was a significant association between c-IMT and UC group with pooled mean difference of 0.127 (95\% CI: 0.058-0.195, p $<0.001$; Figure 2). The considerable statistical heterogeneity was observed $\left(\mathrm{I}^{2}=90.266 \%, \mathrm{p}<0.001\right)$. Funnel plot of the included studies represented the t-value $=0.31$ and $p$-value (2-tailed) $=0.77$ in Egger's regression test that indicate publication bias did not exist for the UC (Figure 3 ).

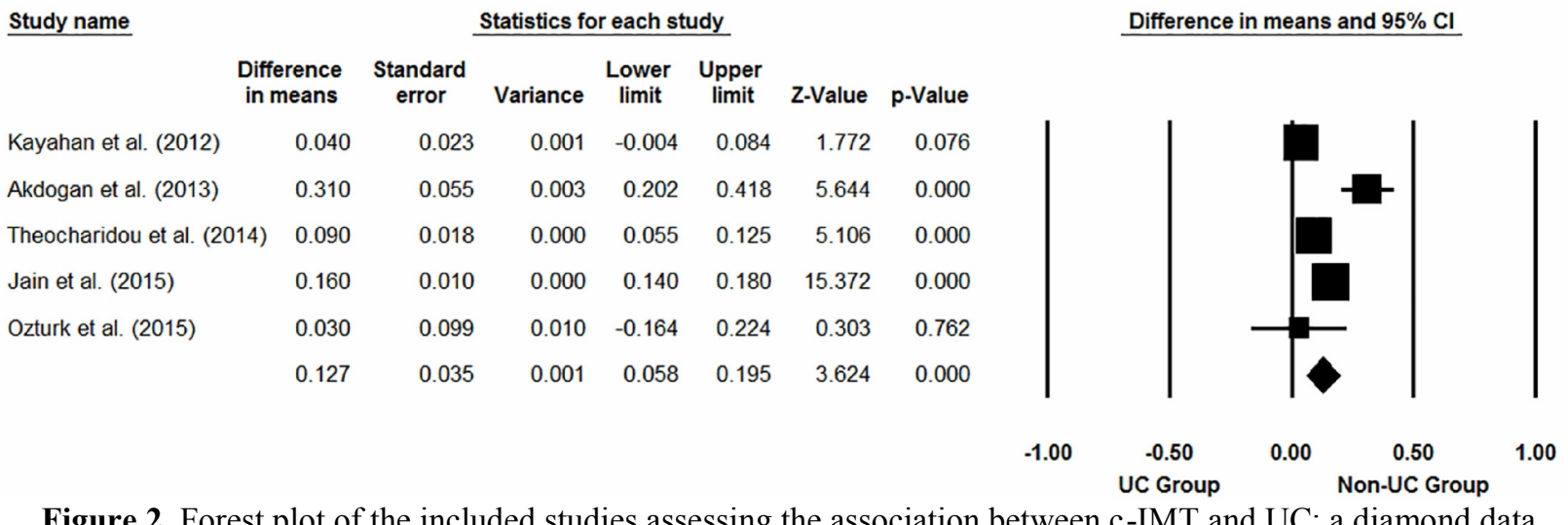

Figure 2. Forest plot of the included studies assessing the association between c-IMT and UC; a diamond data marker represents the overall mean difference estimate, $95 \% \mathrm{CI}$ and Relative weight for the outcome of interest. 


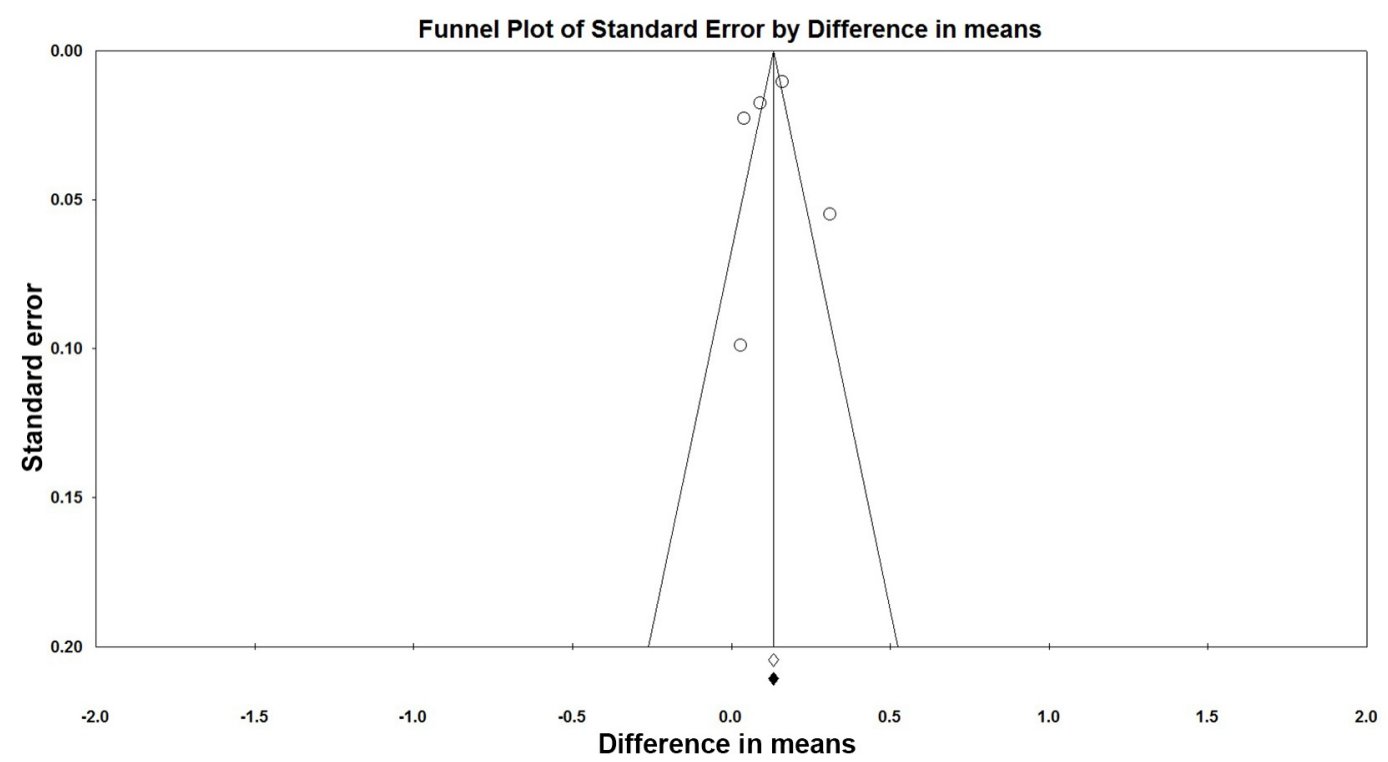

Figure 3. Funnel plot of the included studies represents the $t$-value $=0.31$ and $p$-value (2-tailed) $=0.77$ in Egger's regression test that indicate publication bias did not exist for the UC.

\section{Discussion}

Atherosclerosis is a chronic inflammatory disease considered as a major cause of cardiovascular and cerebrovascular events (22). Therefore, the identification of markers for early diagnosis of atherosclerosis, especially in UC patients is of great importance. Epidemiological studies have shown that a c-IMT $\geq 1 \mathrm{~mm}$ can correlate with increased risk of atherosclerosis and cardiovascular events (23). Although two of five studies included in our systematic review had separately reported that c-IMT was not significantly higher in the UC patients $(15,18)$, the meta-analysis of all included studies showed a significant rise in the UC patients rather than the non-UCs. This finding confirms and correlates with a meta-analysis of sixteen studies which have revealed the same results, while the relationship between c-IMT and UC patients has been evaluated as a secondary outcome measure (6). To our knowledge, this is the first systematic review and meta-analysis specifically focused on the UC patients. Among the two studies that reported no significant association between c-IMT and UC, one had not mentioned disease duration (15) and the other had considered a disease duration of $(4.1 \pm 3.9)$ years $(18)$ which was considerably lower than the other studies (Table 3), and both had obtained considerably lower scores in our quality assessment, done by STROBE measurement. Among the three studies which reported significantly higher c-IMT in UC patients, two had focused on evaluating c-IMT in UC patients as a primary outcome measure $(1,17)$.

Previous studies have discovered an increasing pattern of c-IMT with increasing LDL in IBDs $(6,24)$, but our systematic review, which had concentrated on the UCs did not indicate the exact same results. One study had not reported LDL (15) and from the four studies that did report the LDL, three of them followed the aforementioned pattern $(1,16,18)$, however, one did not (17). In the study of Jain et al, even though c-IMT was reported higher than three other studies, the mean LDLs were the lowest in our review. So, LDL may not be involved in carotid Atherosclerosis. It has been indicated that a low brachial artery FMD percentage is an independent predictor of cardiovascular (CV) risk (25). The two studies which had reported remarkably lower FMD percentage for UC rather than Non-UC patients $(15,18)$, were the studies that indicated no significant relationship between c-IMT and UCs, and the other literatures had not reported FMD percentage by any means. Guo Cui Wu et al. have also found the same finding for IBDs and UCs while the meta-analysis was performed to analyze FMD percentage in IBDs as the main group and in UCs as a subgroup (6). They found that a lower FMD percentage may confer an increased risk of $\mathrm{CV}$ events. The study cannot approve these findings certainly due to unreported FMD percentage in three studies, although two studies reported FMD percentage had indicated lower FMD percentage for UCs rather than Non-UCs. The reported BMI for two groups (UC and Non-UC) was almost the same in four studies, although the studies had reported that BMI was as a risk factor of c-IMT $(10,11,26)$. Also, there were remarkable differences between ESR and CRP in the two groups of UC and non-UC in the studies that had measured them. Eleni Theocharidou et al who had assessed the relationship between c-IMT and IBD reported the same differences for ESR, CRP, and disease duration in two groups of study (IBD and control groups) (12). The results of this systematic review and meta- 
analysis showed that c-IMT is different between the patients with UC and Non-UC controls; therefore, it can be considered as an indicator of atherosclerosis and future cardiovascular disease in patients with UC; hence, significant correlation was found between UC and c-IMT. However, these results may be due to homogeneity of the study population, since almost two thirds of studied patients (257 of 436) were from one country (Turkey). Despite these conflicting results, it has been shown that chronic inflammatory disease such as UC is a risk factor for accelerated atherogenesis and future cardiovascular events (27). However, to prove such association, prospective, long-term, multicenter cohort studies are required.

\section{Limitation and strength of the study}

This was the first study concentrating solely on UC patients for evaluating c-IMT, but our research had a few limitations. First, our meta-analysis included only main groups (UC and Non-UC) for analyzing and we could not perform meta-analysis in subgroups, due to lack of data, which remains for future studies. However, our systematic review included the most factors required to report better information to inform policy makers and specialists. Secondly, we had no plans to make contact with the authors when our required data were not available, but fortunately, we had no such cases and no reason to contact any authors. Third, In spite of our extensive search strategy, we found only five studies relating to evaluating c-IMT in UC patients, two of which, considered UC as a primary outcome measure and three of them had been conducted in Turkey. Finally, the funnel plot and Egger's regression test performed to assess publication bias might not indicate exact result due to lacking included studies. However, we propose to policymakers and specialists, particularly in Iran, to assess the association between c-IMT and UC with proper sample size, long duration of disease and to address all the factors that can act as potential confounders on this relationship.

\section{Conclusions}

The results of this study showed that significant difference existed on c-IMT between UC and Non-UC groups; therefore, this marker can be considered as an early predictor of atherosclerosis and future cardiovascular events in patients with UC. However, further studies are required to prove the association between c-IMT and UC, and to consider all the potential confounding factors which can affect the evaluation of this relationship.

\section{Acknowledgments:}

We want to thank Dr. Azita Ganji and all executive team members of systematic review workshop supported by the Gastroenterology and Hepatology Research Center, Mashhad University of Medical Sciences, Mashhad, Iran.

\section{Conflict of Interest:}

There is no conflict of interest to be declared.

\section{Authors' contributions:}

All authors contributed to this project and article equally. All authors read and approved the final manuscript.

\section{References:}

1) Akdogan RA, Durakoglugil ME, Kocaman SA, Cicek Y, Durakoglugil T, Ergul E, et al. Increased pulse wave velocity and carotid intima-media thickness in patients with ulcerative colitis. Digestive diseases and sciences. 2013; 58(8): 2293-300. doi: 10.1007/s10620-013-2634-9. PMID: 23508984.

2) Loftus EV, Jr. Clinical epidemiology of inflammatory bowel disease: Incidence, prevalence, and environmental influences. Gastroenterology. 2004; 126(6): 1504-17. PMID: 15168363.

3) Cibor D, Domagala-Rodacka R, Rodacki T, Jurczyszyn A, Mach T, Owczarek D. Endothelial dysfunction in inflammatory bowel diseases: Pathogenesis, assessment and implications. World journal of gastroenterology. 2016; 22(3): 1067-77. doi: 10.3748/wjg.v22.i3.1067. PMID: 26811647, PMCID: PMC4716020.

4) Pedersen J, Coskun M, Soendergaard C, Salem M, Nielsen OH. Inflammatory pathways of importance for management of inflammatory bowel disease. World journal of gastroenterology. 2014; 20(1): 64-77. doi: 10.3748/wjg.v20.i1.64. PMID: 24415859, PMCID: PMC3886034.

5) Au K, Singh MK, Bodukam V, Bae S, Maranian P, Ogawa R, et al. Atherosclerosis in systemic sclerosis: a systematic review and meta-analysis. Arthritis and rheumatism. 2011; 63(7): 2078-90. doi: 10.1002/art.30380. PMID: 21480189, PMCID: PMC3128188. 
6) Wu GC, Leng RX, Lu Q, Fan YG, Wang DG, Ye DQ. Subclinical Atherosclerosis in Patients With Inflammatory Bowel Diseases: A Systematic Review and Meta-Analysis. Angiology. 2016. doi: 10.1177/0003319716652031. PMID: 27252243.

7) Jarvisalo MJ, Jartti L, Nanto-Salonen K, Irjala K, Ronnemaa T, Hartiala JJ, et al. Increased aortic intimamedia thickness: a marker of preclinical atherosclerosis in high-risk children. Circulation. 2001; 104(24): 2943-7. doi: 10.1161/hc4901.100522. PMID: 11739310.

8) Kim KO, Jang BI, Lee SH. Does carotid intima-media thickness increase in patients with inflammatory bowel disease? Intest Res. 2014; 12(4): 293-8. PMID: 25374495, PMCID: PMC4214956. doi: 10.5217/ir.2014.12.4.293.

9) Dagli N, Poyrazoglu OK, Dagli AF, Sahbaz F, Karaca I, Kobat MA, et al. Is inflammatory bowel disease a risk factor for early atherosclerosis? Angiology. 2010; 61(2): 198-204. doi: 10.1177/0003319709333869. PMID: 19398421.

10) Papa A, Danese S, Urgesi R, Grillo A, Guglielmo S, Roberto I, et al. Early atherosclerosis in patients with inflammatory bowel disease. European review for medical and pharmacological sciences. 2006; 10(1): 7 11. PMID: 16494104.

11) Papa A, Santoliquido A, Danese S, Covino M, Di Campli C, Urgesi R, et al. Increased carotid intima-media thickness in patients with inflammatory bowel disease. Alimentary pharmacology \& therapeutics. 2005; 22(9): 839-46. doi: 10.1111/j.1365-2036.2005.02657.x. PMID: 16225493.

12) Theocharidou E, Gossios TD, Giouleme O, Athyros VG, Karagiannis A. Carotid intima-media thickness in patients with inflammatory bowel disease: a systematic review. Angiology. 2014; 65(4): 284-93. doi: 10.1177/0003319713477471. PMID: 23423851.

13) Libby P, Ridker PM, Hansson GK. Inflammation in atherosclerosis: from pathophysiology to practice. Journal of the American College of Cardiology. 2009; 54(23): 2129-38. doi: 10.1016/j.jacc.2009.09.009. PMID: 19942084, PMCID: PMC2834169.

14) Stroup DF, Berlin JA, Morton SC, Olkin I, Williamson GD, Rennie D, et al. Meta-analysis of observational studies in epidemiology: a proposal for reporting. Meta-analysis Of Observational Studies in Epidemiology (MOOSE) group. JAMA. 2000; 283(15): 2008-12. PMID: 10789670.

15) Kayahan H, Sari I, Cullu N, Yuksel F, Demir S, Akarsu M, et al. Evaluation of early atherosclerosis in patients with inflammatory bowel disease. Digestive diseases and sciences. 2012; 57(8): 2137-43. doi: 10.1007/s10620-012-2148-x. PMID: 22466100.

16) Theocharidou E, Gossios TD, Griva T, Giouleme O, Douma S, Athyros VG, et al. Is there an association between inflammatory bowel diseases and carotid intima-media thickness? Preliminary data. Angiology. 2014; 65(6): 543-50. doi: 10.1177/0003319713489876. PMID: 23748978.

17) Jain SS, Shah DK, Gambhire PA, Varma RU, Contractor QQ, Rathi PM. Early atherosclerosis in ulcerative colitis: cross-sectional case-control study. Journal of digestive diseases. 2015; 16(11): 656-64. doi: 10.1111/1751-2980.12297. PMID: 26512945.

18) Ozturk K, Guler AK, Cakir M, Ozen A, Demirci H, Turker T, et al. Pulse Wave Velocity, Intima Media Thickness, and Flow-mediated Dilatation in Patients with Normotensive Normoglycemic Inflammatory Bowel Disease. Inflamm Bowel Dis. 2015; 21(6): 1314-20. doi: 10.1097/MIB.0000000000000355. PMID: 25803507, PMCID: PMC4450917.

19) Von Elm E, Altman DG, Egger M, Pocock SJ, Gotzsche PC, Vandenbroucke JP. Strengthening the Reporting of Observational Studies in Epidemiology (STROBE) statement: guidelines for reporting observational studies. BMJ. 2007; 335(7624): 806-8. doi: 10.1136/bmj.39335.541782.AD. PMID: 17947786, PMCID: PMC2034723.

20) Higgins JP, Thompson SG, Deeks JJ, Altman DG. Measuring inconsistency in meta-analyses. BMJ. 2003; 327(7414): 557-60. doi: 10.1136/bmj.327.7414.557. PMID: 12958120, PMCID: PMC192859.

21) Egger M, Davey Smith G, Schneider M, Minder C. Bias in meta-analysis detected by a simple, graphical test. BMJ. 1997; 315(7109): 629-34. PMID: 9310563, PMCID: PMC2127453.

22) Paoletti R, Gotto AM, Hajjar DP. Inflammation in atherosclerosis and implications for therapy. Circulation. 2004; 109(23 suppl 1): III-20-6. doi: 10.1161/01.CIR.0000131514.71167.2e. PMID: 15198962.

23) Simon A, Gariepy J, Chironi G, Megnien JL, Levenson J. Intima-media thickness: a new tool for diagnosis and treatment of cardiovascular risk. J Hypertens. 2002; 20(2): 159-69. PMID: 11821696.

24) Yan F, Tian L, Yu H, Baskota A, Gao Y, Li S, et al. Association of lipoprotein subclasses and carotid intima-media thickness in the Chinese population. Clinical Lipidology. 2014; 9(4): 407-15. doi: 10.2217/clp.14.22. 
25) Yeboah J, Crouse JR, Hsu FC, Burke GL, Herrington DM. Brachial flow-mediated dilation predicts incident cardiovascular events in older adults: the Cardiovascular Health Study. Circulation. 2007; 115(18): 2390-7. doi: 10.1161/CIRCULATIONAHA.106.678276. PMID: 17452608.

26) Rosvall M, Persson M, Ostling G, Nilsson PM, Melander O, Hedblad B, et al. Risk factors for the progression of carotid intima-media thickness over a 16-year follow-up period: the Malmo Diet and Cancer Study. Atherosclerosis. 2015; 239(2): 615-21. doi: 10.1016/j.atherosclerosis.2015.01.030. PMID: 25746169.

27) Schicho R, Marsche G, Storr M. Cardiovascular complications in inflammatory bowel disease. Current drug targets. 2015; 16(3): 181-8. doi: 10.2174/1389450116666150202161500. PMID: 25642719, PMCID: PMC4366573. 